\title{
Robotic mitral valve surgery: A United States multicenter trial
}

\author{
L. Wiley Nifong, MD, ${ }^{a}$ W. R. Chitwood, MD, ${ }^{\text {a }}$ P. S. Pappas, MD, ${ }^{\text {b } ~ C . ~ R . ~ S m i t h, ~ M D, ~}{ }^{c}$ M. Argenziano, MD, ${ }^{c}$
}

V. A. Starnes, MD, ${ }^{d}$ and P. M. Shah, MD, ${ }^{e}$ for the Multi-center Robotic Mitral Repair Group ${ }^{f}$

From the Brody School of Medicine at East Carolina University, Pitt County Memorial Hospital, Greenville, NC, ${ }^{\text {a }}$ Advocate Christ Medical Center, Oak Lawn, Ill, ${ }^{\mathrm{b}}$ Columbia Presbyterian Hospital, New York, NY, University of Southern California, Los Angeles, Calif, ${ }^{\mathrm{d}}$ and Hoag Heart and Vascular Institute, Hoag Memorial Hospital, Newport Beach, Calif ${ }^{\mathrm{e}}$ (see Table 1 for a complete listing of participants and institutions ${ }^{\mathrm{f}}$ ).

Supported in part by an Innovation in Clinical Research Award (Grant 1059) from the Doris Duke Charitable Foundation (New York, NY).

Read at the Eighty-third Annual Meeting of The American Association for Thoracic Surgery, Boston, Mass, May 4-7, 2003.

Received for publication May 1, 2003; revisions received June 21, 2004; accepted for publication July 9, 2004.

Address for reprints: L. Wiley Nifong, MD, Department of Surgery, East Carolina University School of Medicine, 600 Moye Blvd, LSB 248, Greenville, NC 27858 (E-mail: nifongL@mail.ecu.edu).

J Thorac Cardiovasc Surg 2005;129:1395-404 $0022-5223 / \$ 30.00$

Copyright $\odot 2005$ by The American Association for Thoracic Surgery

doi:10.1016/j.jtcvs.2004.07.050
Objective: In a prospective phase II Food and Drug Administration trial, robotic mitral valve repairs were performed in 112 patients at 10 centers by using the da Vinci surgical system. The safety of performing valve repairs with computerized telemanipulation was studied.

Methods: After institutional review board approval, informed consent was obtained. Patients had moderate to severe mitral regurgitation. Operative technique included peripheral cardiopulmonary bypass, a $4-$ to 5 -cm right minithoracotomy, a transthoracic aortic crossclamp, and antegrade cardioplegia. The successful study end point was grade 0 or 1 mitral regurgitation by transthoracic echocardiography at 1 month after surgery.

Results: Valve repairs included quadrangular resections, sliding plasties, edge-toedge approximations, and both chordal transfers and replacements. The average age was $56.4 \pm 0.09$ years (mean \pm SEM). There were 77 (68.8\%) men and $35(31.2 \%)$ women. Valve pathology was myxomatous degeneration in $105(91.1 \%)$, and 103 (92.0\%) had type II leaflet prolapse. Leaflet repair times averaged $36.7 \pm 0.2$ minutes, with annuloplasty times of $39.6 \pm 0.1$ minutes. Total robot, aortic crossclamp, and cardiopulmonary bypass times were $77.9 \pm 0.3$ minutes, $2.1 \pm 0.1$ hours, and $2.8 \pm 0.1$ hours, respectively. On 1-month transthoracic echocardiography, $9(8.0 \%)$ had grade 2 mitral regurgitation, and $6(5.4 \%)$ of these had reoperations (5 replacements and 1 repair). There were no deaths, strokes, or device-related complications.

Conclusions: Multiple surgical teams performed robotic mitral valve repairs safely early in development of this procedure, with a reoperation rate of $5.4 \%$. Advancements in robotic design and adjunctive technologies may help in the evolution of this minimally invasive technique by decreasing operative times.

$\mathrm{T}$ raditionally, cardiac surgery has been performed through a median sternotomy providing surgeons with generous operative exposure. Since 1995, improvements in perfusion technology and instrumentation have stimulated cardiac surgeons to investigate the efficacy of minimally invasive cardiac procedures. In large series of patients, Cohn and colleagues, ${ }^{1}$ Cosgrove and colleagues, ${ }^{2}$ and Navia and Cosgrove ${ }^{3}$ first reported improved outcomes and economic benefits with minimal-access mitral valve (MV) and aortic valve surgery. Subsequently, further developments in intracardiac visualization, instrumentation, and cannulation methods hastened the development and expansion of minimally invasive cardiac surgery. ${ }^{4,5}$ Because of these improvements, valve surgery performed through small incisions is now standard practice for many surgeons.

Telemanipulation of tissues has become possible through recent advances in surgical robotic systems, which provide a combination of 3-dimensional vision and microinstrumentation providing a full range of motion in tiny spaces, no tremor, and motion scaling. 
TABLE 1. Institutions and investigators

\begin{tabular}{ll}
\hline Site & \multicolumn{1}{c}{ Investigators } \\
\hline East Carolina University & CS: W. Randolph Chitwood Jr \\
Greenville, NC & PSS: L. Wiley Nifong \\
Advocate Christ Hospital & CS: Pat Pappas \\
Oak Lawn, III & PSS: Anthony Tatooles \\
Columbia Presbyterian Hospital & CS: Craig Smith \\
$\quad$ New York, NY & PSS: Michael Argenziano \\
University of Southern California & CS: Vaughn Starnes \\
Los Angeles, Calif & PSS: Daniel Schwarz \\
St Vincent's Hospital & CS: Jeffrey Swanson \\
Portland, Ore & PSS: Michael Savitt \\
Carillon Roanoke Memorial Hospital & CS: Joseph Baker \\
Roanoke, Va & PSS: Paul Frantz \\
INNOVA Fairfax Hospital & CS: Paul Massimiano \\
Fairfax, Va & PSS: Edward Lefrak \\
Ohio State University & CS: Robert Michler \\
Columbus, Ohio & PSS: David Brown \\
Brigham \& Women's Hospital & CS: Lawrence Cohn \\
Boston, Mass & PSS: Lishan Aklog \\
Baylor Healthcare System & CS: Robert Hebeler \\
Dallas, Tex & PSS: Richard Wood
\end{tabular}

CS, Console surgeon; PSS, patient side surgeon.

In 1998, Carpentier and Mohr independently performed the first MV repairs by using an early prototype of the da Vinci surgical system (Intuitive Surgical, Inc, Sunnyvale, Calif). ${ }^{6,7}$ Mohr and colleagues ${ }^{8}$ then reported the first operative series of robotic MV procedures. Mehmnesh and colleagues ${ }^{9}$ have performed the only closed-chest endoscopic MV repair to date. Using the Zeus system, Grossi and colleagues ${ }^{10}$ performed a posterior leaflet repair in 2000. A month later, with the da Vinci system, Chitwood and colleagues ${ }^{11}$ performed a posterior leaflet resection with reconstruction and implanted an annuloplasty band.

\section{TABLE 2. Robotic mitral surgery exclusion criteria}

\begin{tabular}{l}
\hline$<18$ or $>80$ y of age \\
Previous right thoracotomy \\
Renal failure \\
Liver dysfunction \\
Bleeding disorders \\
Pulmonary hypertension (pulmonary artery systolic pressure \\
$>60 \mathrm{~mm} \mathrm{Hg}$ ) \\
Concomitant MV stenosis \\
Anterior MV leaflet disease \\
Significant aortic or tricuspid valve disease \\
Coronary artery disease requiring surgery \\
Recent myocardial ischemia $(<30 \mathrm{~d}$ ) \\
Recent stroke ( $<30 \mathrm{~d}$ ) \\
Severely calcified mitral valve annulus \\
Body mass index $>35 \mathrm{~kg} / \mathrm{m}^{2}$
\end{tabular}

A phase I clinical trial (G000023) approved by the Food and Drug Administration (FDA) was begun at East Carolina University (ECU) to evaluate safety and efficacy in robotassisted MV repair surgery. In this initial series, patients were between 18 and 80 years of age and had isolated grade 3/4 mitral regurgitation. All 10 patients had successful MV repairs, with no deaths or complications. ${ }^{12}$ The FDA extended this trial to 20 patients to provide training observation at ECU in preparation for the forthcoming phase II trial. In October 2000, an FDA-approved multicenter phase II trial (G000295) was initiated to evaluate the system in a variety of institutional environments. This report describes results from this 10-center multicenter phase II clinical trial evaluating the da Vinci surgical system in $112 \mathrm{MV}$ repair patients.

\section{Patients and Methods}

Patients were enrolled by using FDA-approved selection criteria after full institutional review board (IRB) approval at the respective institutions (Table 1). Each patient signed both IRB- and FDA-approved consent forms after informed consent was obtained. Between February 2001 and July 2002, 112 patients were enrolled. Patients between 18 and 80 years of age with echocardiographically confirmed moderate (grade 3 ) to severe (grade 4) regurgitation requiring a repair were screened for participation. All patients underwent a history and physical examination followed by a chest radiograph and transthoracic echocardiogram (TTE). Quantitation of valve regurgitation was obtained by Doppler color flow imaging, spectral Doppler, and imaging for flow acceleration, as well as measurement of proximal isovelocity surface area. The severity of the regurgitant jet was assessed by parameters includ- 
TABLE 3. MV pathology and etiology

\begin{tabular}{|c|c|c|c|c|c|c|c|c|c|c|c|}
\hline Variable & $\begin{array}{c}\text { Total } \\
(\mathrm{n}=112)\end{array}$ & $\begin{array}{c}\text { BAY } \\
(n=3)\end{array}$ & $\begin{array}{c}\text { BWH } \\
(n=4)\end{array}$ & $\begin{array}{c}\text { CAR } \\
(n=8)\end{array}$ & $\begin{array}{c}\text { COL } \\
(n=15)\end{array}$ & $\begin{array}{c}\text { CRH } \\
(n=20)\end{array}$ & $\begin{array}{c}\text { ECU } \\
(n=22)\end{array}$ & $\begin{array}{c}\text { FRX } \\
(n=9)\end{array}$ & $\begin{array}{c}\text { OSU } \\
(n=7)\end{array}$ & $\begin{array}{c}\text { STV } \\
(n=11)\end{array}$ & $\begin{array}{c}\text { USC } \\
(n=13)\end{array}$ \\
\hline \multicolumn{12}{|l|}{ Etiology } \\
\hline Myxomatous & $105(91.1)$ & $3(100)$ & $4(100)$ & $8(100)$ & $12(80.0)$ & $20(100)$ & $19(86.4)$ & $9(100)$ & $6(85.7)$ & $11(100)$ & $13(100)$ \\
\hline Other & $7(6.3)$ & 0 & 0 & 0 & $3(20.0)$ & 0 & $3(13.6)$ & 0 & $1(14.3)$ & 0 & 0 \\
\hline \multicolumn{12}{|l|}{ Leaflet dysfunction* } \\
\hline Type I & $5(4.5)$ & 0 & 0 & 0 & $1(6.6)$ & 0 & $1(4.6)$ & 0 & $2(28.6)$ & $1(9.1)$ & 0 \\
\hline Type II & $103(92.0)$ & $3(100)$ & $4(100)$ & $8(100)$ & $14(93.3)$ & $20(100)$ & $19(86.4)$ & $9(100)$ & $5(71.4)$ & $10(90.9)$ & 11 (84.6) \\
\hline Type III & $1(1.7)$ & 0 & 0 & 0 & 0 & 0 & $1(4.6)$ & 0 & 0 & 0 & 0 \\
\hline Other & $3(2.7)$ & 0 & 0 & 0 & 0 & 0 & $1(4.6)$ & 0 & 0 & 0 & $2(15.4)$ \\
\hline \multicolumn{12}{|l|}{ Valve pathology } \\
\hline Leaflet prolapse & $105(93.8)$ & $3(100)$ & $4(100)$ & $8(100)$ & 14 (93.3) & $20(100)$ & $19(86.4)$ & $9(100)$ & $5(71.4)$ & $10(90.9)$ & $13(100)$ \\
\hline Chordal rupture & $63(56.3)$ & $1(33.3)$ & $3(75.0)$ & $1(12.5)$ & $6(40.0)$ & $12(60.0)$ & $12(54.6)$ & 7 (77.8) & $3(42.9)$ & $9(81.8)$ & $9(69.2)$ \\
\hline $\begin{array}{l}\text { Isolated annular } \\
\text { dilatation }\end{array}$ & $6(5.4)$ & 0 & 0 & 0 & $1(6.7)$ & 0 & $2(9.1)$ & 0 & $2(28.6)$ & $1(9.1)$ & 0 \\
\hline Leaflet perforation & $1(0.9)$ & 0 & 0 & 0 & $1(6.7)$ & 0 & 0 & 0 & 0 & 0 & 0 \\
\hline
\end{tabular}

BAY, Baylor Healthcare System; BWH, Brigham \& Women's Hospital; CAR, Carillon Roanoke Memorial Hospital; COL, Columbia Presbyterian Hospital; CRH, Advocate Christ Hospital; ECU, East Carolina University; FRX, INNOVA Fairfax Hospital; OSU, Ohio State University; STV, St Vincent's Hospital; USC, University of Southern California. Data are $\mathrm{n}(\%)$. * Leaflet dysfunction as defined by the Carpentier classification. ${ }^{15}$

TABLE 4. Mitral valve repair techniques

\begin{tabular}{|c|c|c|c|c|c|c|c|c|c|c|c|}
\hline Variable & $\begin{array}{c}\text { Total } \\
(\mathrm{n}=112)\end{array}$ & $\begin{array}{c}\text { BAY } \\
(n=3)\end{array}$ & $\begin{array}{l}\text { BWH } \\
(n=4)\end{array}$ & $\begin{array}{c}\text { CAR } \\
(n=8)\end{array}$ & $\begin{array}{c}\text { COL } \\
(n=15)\end{array}$ & $\begin{array}{c}\text { CRH } \\
(n=20)\end{array}$ & $\begin{array}{c}\text { ECU } \\
(n=22)\end{array}$ & $\begin{array}{c}\text { FRX } \\
(n=9)\end{array}$ & $\begin{array}{c}\text { OSU } \\
(n=7)\end{array}$ & $\begin{array}{c}\text { STV } \\
(\mathrm{n}=11)\end{array}$ & $\begin{array}{c}\text { USC } \\
(n=13)\end{array}$ \\
\hline $\begin{array}{l}\text { Isolated annuloplasty } \\
\qquad(P=.06)\end{array}$ & $11(9.8)$ & $1(33.3)$ & 0 & 0 & $1(6.7)$ & 0 & $3(13.6)$ & 0 & $3(42.9)$ & $2(18.2)$ & $1(7.7)$ \\
\hline $\begin{array}{l}\text { Quadrangular } \\
\text { resection } \\
\qquad(P<.0001)\end{array}$ & 81 (72.3) & $2(66.7)$ & $4(100)$ & $8(100)$ & $13(86.7)$ & $20(100)$ & $14(63.6)$ & $9(100)$ & $4(57.1)$ & 7 (63.6) & 0 \\
\hline $\begin{array}{l}\text { Sliding plasty } \\
\qquad(P=.0002)\end{array}$ & $5(4.5)$ & $2(66.7)$ & 0 & 0 & $1(6.7)$ & 0 & $2(9.1)$ & 0 & 0 & 0 & 0 \\
\hline $\begin{array}{l}\text { Chordal repair, } \\
\text { replacement, or } \\
\text { shortening } \\
(P<.0001)\end{array}$ & $15(13.4)$ & 0 & 0 & 0 & 0 & 0 & $2(9.1)$ & $1(9.1)$ & 0 & 0 & 12 (92.3) \\
\hline
\end{tabular}

BAY, Baylor Healthcare System; BWH, Brigham \& Women's Hospital; CAR, Carillon Roanoke Memorial Hospital; COL, Columbia Presbyterian Hospital; CRH, Advocate Christ Hospital; ECU, East Carolina University; FRX, INNOVA Fairfax Hospital; OSU, Ohio State University; STV, St Vincent's Hospital; USC, University of Southern California. Data are $\mathrm{n}(\%)$.

ing the superior extent of the jet reaching the left atrial roof, penetration into 1 or both upper pulmonary veins, and penetration into the left atrial appendage. Subject exclusion criteria are outlined in Table 2. Each surgical team was trained at the Surgical Robotic Training Center at ECU by using a curriculum-based program that included case observation, didactic sessions, and both inanimate and cadaver models. ${ }^{13}$

All patients were intubated for single-lung ventilation. Both a pulmonary artery catheter and a $17 \mathrm{~F}$ venous drainage cannula were placed percutaneously into the right internal jugular vein. A transesophageal echocardiographic (TEE) probe was positioned after intubation. External defibrillator patches were placed to subtend the maximum cardiac mass. Each patient was positioned with the right chest elevated approximately $40^{\circ}$ and with the right arm suspended on a padded armrest above the forehead. Femoral arterial and venous cannulation was performed through a 2-cm transverse right groin incision by using the Seldinger guidewire method and TEE guidance. Bicaval venous drainage was instituted through the jugular and femoral/ inferior vena cava cannulas. A 5- to 6-cm submammary right minithoracotomy was made, and the fourth intercostal space (ICS) was entered after right lung deflation. The details of intrathoracic preparation have been described in other publications. ${ }^{14}$ Cardioplegia administration routes varied depending on institutional choice. Aortic occlusion was performed by using either a transthoracic crossclamp or an endoaortic balloon. Carbon dioxide was insufflated continuously into the operative field for air displacement. An interatrial groove left atriotomy was performed, and each MV was exposed by using a transthoracic intra-atrial retractor (CardioVations, Somerville, NJ). 
TABLE 5. Operative characteristics, including times

\begin{tabular}{|c|c|c|c|c|c|c|c|c|c|c|c|}
\hline Variable & $\begin{array}{c}\text { Total } \\
\text { (n = 112) }\end{array}$ & $\begin{array}{c}\text { BAY } \\
(n=3)\end{array}$ & $\begin{array}{c}\text { BWH } \\
(n=4)\end{array}$ & $\begin{array}{c}\text { CAR } \\
(n=8)\end{array}$ & $\begin{array}{c}\text { COL } \\
(n=15)\end{array}$ & $\begin{array}{c}\text { CRH } \\
(n=20)\end{array}$ & $\begin{array}{c}\text { ECU } \\
(n=22)\end{array}$ & $\begin{array}{c}\text { FRX } \\
(n=9)\end{array}$ & $\begin{array}{c}\text { OSU } \\
(n=7)\end{array}$ & $\begin{array}{c}\text { STV } \\
(n=11)\end{array}$ & $\begin{array}{c}\text { USC } \\
(n=13)\end{array}$ \\
\hline \multicolumn{12}{|c|}{ Operation time $(P<.0001)$ (min) } \\
\hline Mean & 266.4 & 309.0 & 334.3 & 243.8 & 386.0 & 199.7 & 265.1 & 295.7 & 269.6 & 255.5 & 203.7 \\
\hline SD & 73.0 & 55.7 & 43.4 & 23.6 & 48.3 & 35.1 & 47.7 & 53.0 & 62.0 & 28.5 & 46.8 \\
\hline Range & $150-463$ & $263-371$ & 298-392 & $218-286$ & 293-463 & $154-287$ & $198-372$ & $247-414$ & $201-382$ & $196-292$ & $150-306$ \\
\hline \multicolumn{12}{|c|}{ CPB time $(P<.0001)$ (min) } \\
\hline Mean & 168.8 & 164.3 & 222.3 & 193.3 & 227.3 & 126.9 & 162.7 & 201.7 & 164.4 & 164.5 & 128.9 \\
\hline SD & 47.3 & 8.7 & 54.0 & 10.5 & 52.6 & 24.3 & 28.5 & 42.3 & 35.7 & 25.0 & 27.5 \\
\hline Range & $82-316$ & 157-174 & $175-300$ & $173-205$ & $140-316$ & $95-175$ & $113-216$ & $166-300$ & $117-223$ & 113-188 & $82-183$ \\
\hline \multicolumn{12}{|c|}{ Aortic crossclamp time $(P<.0001)(\min )$} \\
\hline Mean & 124.1 & 131.3 & 173.3 & 135.6 & 145.3 & 89.8 & 124.6 & 152.2 & 134.9 & 132.5 & 95.5 \\
\hline SD & 34.0 & 11.0 & 36.9 & 14.1 & 30.9 & 22.3 & 20.3 & 35.8 & 39.2 & 26.6 & 18.9 \\
\hline Range & $60-227$ & $124-144$ & $148-227$ & $112-156$ & $96-213$ & $60-143$ & $87-163$ & $117-226$ & $82-196$ & $83-177$ & $67-136$ \\
\hline \multicolumn{12}{|c|}{ da Vinci time $(P<.0001)(\min )$} \\
\hline Mean & 77.9 & 44.7 & 114.5 & 84.1 & 109.9 & 65.6 & 86.8 & 79.2 & 66.9 & 72.6 & 46.5 \\
\hline SD & 30.3 & 15.0 & 18.7 & 13.2 & 34.1 & 24.2 & 16.1 & 30.0 & 31.3 & 27.9 & 14.1 \\
\hline Range & 21-171 & $28-57$ & $97-141$ & $60-97$ & $61-171$ & $42-128$ & $52-128$ & $60-152$ & $21-115$ & $25-113$ & $29-75$ \\
\hline \multicolumn{12}{|c|}{ Annuloplasty time $(P<.0001)(\mathrm{min})$} \\
\hline Mean & 39.6 & 44.0 & 52.5 & 38.9 & 50.5 & 28.1 & 42.4 & 46.9 & 47.0 & 37.5 & 28.2 \\
\hline SD & 13.6 & 6.6 & 3.5 & 4.1 & 13.5 & 6.7 & 13.5 & 11.0 & 14.7 & 13.7 & 9.1 \\
\hline Range & 17-79 & $37-50$ & $49-56$ & $33-45$ & $34-76$ & $19-40$ & $27-79$ & $38-74$ & $25-70$ & $17-56$ & $20-54$ \\
\hline \multicolumn{12}{|c|}{ Leaflet repair time $(P<.0001)$ (min) } \\
\hline $\mathrm{n}$ & 101 & 2 & 4 & 8 & 14 & 20 & 19 & 9 & 4 & 9 & 12 \\
\hline Mean & 36.7 & 36.0 & 45.8 & 39.6 & 48.1 & 20.7 & 38.9 & 48.3 & 61.3 & 51.8 & 13.3 \\
\hline SD & 20.4 & 1.4 & 10.3 & 12.2 & 25.7 & 11.9 & 14.7 & 11.1 & 17.5 & 18.5 & 8.6 \\
\hline Range & 5-115 & $35-37$ & $35-38$ & $22-60$ & $20-115$ & $9-53$ & $19-67$ & $33-70$ & $49-87$ & $29-84$ & $5-36$ \\
\hline
\end{tabular}

BAY, Baylor Healthcare System; BWH, Brigham \& Women's Hospital; CAR, Carillon Roanoke Memorial Hospital; COL, Columbia Presbyterian Hospital; CRH, Advocate Christ Hospital; ECU, East Carolina University; FRX, INNOVA Fairfax Hospital; OSU, Ohio State University; STV, St Vincent's Hospital; USC, University of Southern California; $C P B$, cardiopulmonary bypass.

da Vinci instrument arms $(7 \mathrm{~mm})$ were inserted through two $10-\mathrm{mm}$ trocar incisions. The right instrument arm generally was positioned 4 to $6 \mathrm{~cm}$ lateral to the chest incision in either the fourth or fifth ICS. The left instrument arm was positioned medial and cephalad to the right arm in the second or third ICS. Arm trocar sites were maintained $6 \mathrm{~cm}$ apart at chest entry. Care was taken to establish optimal arm-vector alignment with the valve plane to ensure full, unrestricted instrument excursion. A specialized $30^{\circ}$ stereoscopic endoscope was placed through the medial portion of the minithoracotomy. A patient-side surgeon facilitated instrument changes and needle/suture passing and retrieval. All valve repair and annuloplasty sutures were placed with the da Vinci robot. All left atriotomies were closed either under direct vision or with videoscopic assistance. After crossclamp release, meticulous intracardiac deairing and weaning from cardiopulmonary bypass (CPB) was performed, and pacing wires and chest tubes were inserted. In each patient, a postrepair TEE was performed for analysis by the outside echocardiographic core laboratory.

Clinical information for enrolled patients was collected and verified by trained study monitors. All data were abstracted onto FDA case report forms and entered into a database. Case report forms were completed for the following points: (1) before surgery, (2) during surgery, (3) after surgery (including the intensive care unit), (4) at discharge, and (5) 1 month after surgery. All adverse events were recorded and reported immediately. All echocardiograms were reviewed by an independent core laboratory (Hoag Memorial Hospital, Newport Beach, Calif). These included preoperative TTE, intraoperative TEE before and after each MV repair, and a TTE 1 month after surgery. Intraoperative TEE was performed before institution of CPB and after the valve repair after weaning from bypass. The core laboratory was blinded to echocardiogram findings at each site, and individual sites were blinded to the core laboratory findings. Significant discrepancies were resolved by reanalysis of the echocardiography tapes in question. The core laboratory assessment was used in the final analysis.

All final data analyses were conducted with SAS (SAS Institute, Cary, NC). All continuous variables were analyzed with nonparametric tests, the Wilcoxon ranked sum test for 2-group comparisons, and Kruskal-Wallis analysis of variance for multigroup comparisons. Categorical data were analyzed with $\chi^{2}$ tests. Data are shown as mean \pm SD and range.

\section{Results}

Between February 2001 and July 2002, 112 patients with grade 3/4 mitral regurgitation underwent a robotic MV repair with the da Vinci surgical system. Operation at each site was performed by the same console surgeon and up to 
TABLE 6. Postoperative characteristics, including times

\begin{tabular}{|c|c|c|c|c|c|c|c|c|c|c|c|}
\hline Variable & $\begin{array}{c}\text { Total } \\
(\mathrm{n}=112)\end{array}$ & $\begin{array}{c}\text { BAY } \\
(n=3)\end{array}$ & $\begin{array}{c}\text { BWH } \\
(n=4)\end{array}$ & $\begin{array}{c}\text { CAR } \\
(n=9)\end{array}$ & $\begin{array}{c}\text { COL } \\
(n=4)\end{array}$ & $\begin{array}{c}\text { CRH } \\
(n=20)\end{array}$ & $\begin{array}{c}\text { ECU } \\
(n=22)\end{array}$ & $\begin{array}{c}\text { FRX } \\
(n=9)\end{array}$ & $\begin{array}{c}\text { OSU } \\
(n=7)\end{array}$ & $\begin{array}{c}\text { STV } \\
(n=11)\end{array}$ & $\begin{array}{c}\text { USC } \\
(n=13)\end{array}$ \\
\hline \multicolumn{12}{|c|}{ Ventilation time (h) } \\
\hline Mean & 9.1 & 6.3 & 15.3 & 5.5 & 19.5 & 0.8 & 10.6 & 6.7 & 12.3 & 5.5 & 11.8 \\
\hline SD & 12.6 & 1.2 & 17.9 & 3.0 & 27.1 & 1.7 & 5.3 & 4.4 & 5.0 & 5.0 & 11.2 \\
\hline Range & $0-112$ & $5-7$ & $5-42$ & $2-10$ & $2-112$ & $0-5$ & $4-31$ & $3-17$ & $7-19$ & $2-20$ & $3-43$ \\
\hline \multicolumn{12}{|c|}{ ICU time (h) } \\
\hline Mean & 36.6 & 31.3 & 53.0 & 26.5 & 48.2 & 37.2 & 25.8 & 30.7 & 32.3 & 30.2 & 55.0 \\
\hline SD & 24.7 & 12.1 & 45.1 & 9.6 & 41.8 & 20.3 & 13.0 & 13.7 & 13.5 & 12.2 & 27.3 \\
\hline Range & 6-140 & $22-45$ & $22-119$ & $21-50$ & $17-140$ & $6-81$ & $8-70$ & $19-56$ & $20-52$ & $19-51$ & $16-98$ \\
\hline \multicolumn{12}{|c|}{ Length of stay (d) } \\
\hline Mean & 4.7 & 6.3 & 7.0 & 4.4 & 6.3 & 2.8 & 4.3 & 3.9 & 4.9 & 6.1 & 5.1 \\
\hline SD & 3.0 & 0.6 & 6.0 & 1.7 & 3.5 & 3.4 & 1.6 & 1.0 & 1.1 & 4.6 & 2.0 \\
\hline Range & $1-18$ & $6-7$ & $4-16$ & $3-7$ & 3-18 & $1-16$ & $3-9$ & $2-5$ & $4-7$ & $3-18$ & $3-9$ \\
\hline
\end{tabular}

$B A Y$, Baylor Healthcare System; BWH, Brigham \& Women's Hospital; CAR, Carillon Roanoke Memorial Hospital; COL, Columbia Presbyterian Hospital; CRH, Advocate Christ Hospital; ECU, East Carolina University; FRX, INNOVA Fairfax Hospital; OSU, Ohio State University; STV, St Vincent's Hospital; USC, University of Southern California; ICU, intensive care unit.

TABLE 7. Intraoperative TEE by the core echocardiography laboratory

\begin{tabular}{|c|c|c|c|c|c|c|c|c|c|c|c|}
\hline Variable & Total & BAY & BWH & CAR & COL & CRH & ECU & FRX & OSU & STV & USC \\
\hline \multicolumn{12}{|c|}{ Prerepair regurgitation grade } \\
\hline Number & 107 & 3 & 3 & 8 & 14 & 19 & 21 & 8 & 7 & 11 & 13 \\
\hline None & - & - & - & - & - & - & - & - & - & - & - \\
\hline 1 & - & - & - & - & - & - & - & - & - & - & - \\
\hline 2 & $3(2.8)$ & 0 & 0 & 0 & $1(7.1)$ & 0 & $1(4.8)$ & 0 & $1(14.3)$ & 0 & 0 \\
\hline 3 & $68(63.6)$ & $3(100)$ & $2(66.7)$ & $6(75)$ & $6(42.9)$ & $15(78.9)$ & $15(71.4)$ & $2(25)$ & $4(57.1)$ & $8(72.7)$ & $7(53.8)$ \\
\hline 4 & $36(33.6)$ & 0 & $1(33.3)$ & $2(25)$ & $7(50)$ & $4(21.1)$ & $5(23.8)$ & $6(75)$ & $2(28.6)$ & $3(27.3)$ & $6(46.1)$ \\
\hline Not reported & 5 & & & & & & & & & & \\
\hline \multicolumn{12}{|c|}{ Postrepair regurgitation grade } \\
\hline Number & 108 & 3 & 4 & 7 & 14 & 20 & 21 & 8 & 7 & 11 & 13 \\
\hline None & $78(72.2)$ & $3(100)$ & $1(25.0)$ & $5(71.4)$ & $9(64.3)$ & $12(60.0)$ & $15(71.4)$ & $7(87.5)$ & $6(85.7)$ & $9(81.8)$ & $11(84.6)$ \\
\hline 1 & $29(26.9)$ & 0 & $3(75.0)$ & $1(14.3)$ & $5(35.7)$ & $8(40.0)$ & $6(28.6)$ & $1(12.5)$ & $1(14.3)$ & $2(18.2)$ & $2(15.4)$ \\
\hline 2 & $1(0.9)$ & 0 & 0 & $1(14.3)$ & 0 & 0 & 0 & 0 & 0 & 0 & 0 \\
\hline 3 & - & - & - & - & - & - & - & - & - & - & - \\
\hline 4 & - & - & - & - & - & - & - & - & - & - & - \\
\hline Not reported & 4 & & & & & & & & & & \\
\hline
\end{tabular}

$B A Y$, Baylor Healthcare System; BWH, Brigham \& Women's Hospital; CAR, Carillon Roanoke Memorial Hospital; COL, Columbia Presbyterian Hospital; CRH, Advocate Christ Hospital; ECU, East Carolina University; FRX, INNOVA Fairfax Hospital; OSU, Ohio State University; STV, St Vincent's Hospital; USC, University of Southern California. Data are $\mathrm{n}(\%)$.

2 patient-side surgeons. At study initiation, 324 patients met the initial screening criteria; however, 212 (65.4\%) patients were ineligible because of issues related to the inclusion/ exclusion criteria (Table 2). Ineligibility was due to concomitant coronary artery disease $(n=61 ; 30.8 \%)$, tricuspid valve disease $(\mathrm{n}=49 ; 24.7 \%)$, aortic insufficiency/stenosis $(\mathrm{n}=15 ; 7.5 \%)$, and anterior MV leaflet disease requiring repair $(\mathrm{n}=15 ; 7.5 \%)$. One hundred twelve patients $(34.6 \%)$ were enrolled in the study.

The average age of all patients was $56.4 \pm 10.2$ years, with a range of 37 to 81 years. The average body mass index was $26.6 \pm 4.0 \mathrm{~kg} / \mathrm{m}^{2}\left(18.5\right.$ to $\left.40.9 \mathrm{~kg} / \mathrm{m}^{2}\right)$. Of the 112 patients, 77 were male $(68.8 \%)$, and $102(91.1 \%)$ were white. The most prevalent comorbid conditions were a family history of coronary artery disease $(\mathrm{n}=59 ; 52.7 \%)$, smoking $(\mathrm{n}=39 ; 34.8 \%)$, cardiac arrhythmias $(\mathrm{n}=33$; $29.5 \%)$, hypertension $(\mathrm{n}=39 ; 34.8 \%)$, congestive heart failure $(n=22 ; 19.6 \%)$, and cardiomegaly $(n=20 ; 17.9 \%)$. There was a significantly lower prevalence of peripheral vascular disease $(\mathrm{n}=5 ; 4.5 \%)$, infectious endocarditis $(\mathrm{n}=$ $6 ; 5.6 \%)$, diabetes $(\mathrm{n}=3 ; 2.6 \%)$, and rheumatic fever $(\mathrm{n}=$ $6 ; 5.6 \%)$. No statistically significant differences in demographic characteristics were found among the patients enrolled. 
Table 3 shows both the pathologies and etiologies of regurgitation in these patients. As expected, most patients had myxomatous MV degeneration $(\mathrm{n}=105 ; 91.1 \%)$, resulting primarily in Carpentier classification type II leaflet prolapse $(n=103 ; 92.0 \%) .{ }^{15}$ Although prolapse was observed most often, approximately half of the patients had other reasons for valvular insufficiency, including chordal rupture $(\mathrm{n}=65 ; 56.3 \%)$ and isolated annular dilatation $(\mathrm{n}=$ $6 ; 5.4 \%)$. Of the 112 patients, $101(90.2 \%)$ had a valvuloplasty, and all $112(100 \%)$ had a posterior band annuloplasty. As seen in Table 4, the most common valvuloplasty performed was a leaflet resection $(\mathrm{n}=81 ; 72.3 \%)$. In addition, 15 (13.4\%) patients had a chordal repair, prosthetic replacement, or transfer.

Intraoperative procedural times are shown in Table 5. Of the 101 patients undergoing leaflet repairs, the average time required for excision and reconstruction was $36.7 \pm 20.4$ minutes (range, 5-115 minutes). The 112 annuloplasty band implantations averaged 39.6 \pm 13.6 minutes (range, 17-79 minutes) to complete. Mean aortic crossclamp and CPB times were $124.1 \pm 34.0$ minutes (range, 60-227 minutes) and $168.8 \pm 47.3$ minutes (range, 82-316 minutes), respectively. Finally, the average time for da Vinci system use was $77.9 \pm 30.3$ minutes (range, 21-171 minutes). Of the 112 patients, $25(22.3 \%)$ required intraoperative or postoperative blood replacement products. The 19 patients transfused with packed red blood cells (16.9\%) required an average of $2.5 \pm 0.9$ units (range, 1 to 4 units), and 5 patients (4.5\%) received $2.6 \pm 1.1$ units (range, 1-4 units) of fresh frozen plasma. Six (5.4\%) patients were transfused with $4.0 \pm 2.6$ units (range, 1-8 units) of platelets. Intubation, intensive care, and total hospitalization times are shown in Table 6 . The mean ventilation time for the group was $9.1 \pm 12.6$ hours (range, 0-112 hours), with ICU stays averaging 36.6 \pm 24.7 hours (range, 6-140 hours). The length of hospital stay for all patients was $4.7 \pm 3.0$ days (range, 1-18 days).

All patients had a preoperative TTE within 1 month of trial enrollment. Of the 112 patients, 109 (97.3\%) had either grade 3 or 4 regurgitation. The mean preoperative left ventricular ejection fraction was $64.1 \% \pm 6.8 \%$ (range, $35 \%-75 \%$ ). The Kruskal-Wallis test for analysis of variance showed no significant differences in the severity of either MV regurgitation or left ventricular ejection fraction across institutions ( $P=.5$ and $P=.22$, respectively). The intraoperative TEE results before and after surgical repairs are shown in Table 7. The prerepair TEE results were similar to the results of the TTE studies. Of the 107 patients with a prerepair intraoperative TEE, 104 (97.2\%) had either grade 3 or 4 mitral regurgitation. Of the 107 patients with TEE results, $79(73.8 \%)$ had isolated posterior leaflet disease, whereas $26(24.3 \%)$ had some involvement of both the posterior and anterior leaflets. The postrepair intraoperative TEE showed all but 1 patient to have either grade 1 or no
MV regurgitation. Immediate postoperative TEE results confirmed reversion in $99.1 \%$ of patients from grade $3 / 4$ regurgitation to either grade 1 or no leak. No significant differences in either preoperative or postoperative regurgitation grades were found across sites $(P=.32$ and $P=.05$, respectively).

Of the 112 patients enrolled in the study, 1-month postoperative follow-up TTE showed that $103(92.0 \%)$ had either no or grade 1 regurgitation. Seven $(6.3 \%)$ had grade 2 regurgitation, and $2(1.8 \%)$ had either grade 3 or 4 leaks. Of these 9 patients, 3 with grade 2 regurgitation are being followed up and have not required reoperation because they have no clinical symptoms. The first of these 3 patients had a type II posterior leaflet prolapse with chordal ruptures and elongations, combined with annular dilatation. A posterior leaflet resection was performed along with a band annuloplasty. The postrepair TEE showed no regurgitation. The second patient had a restricted posterior mitral leaflet with thickened edges. A posterior annuloplasty was performed with no leaflet resection. The immediate postrepair TEE showed grade 1 regurgitation. The third patient had Barlow disease with prolapse of the anterior $\mathrm{A}_{2}$ and posterior $\mathrm{P}_{2}$ leaflet segments. An edge-to-edge leaflet repair was performed, followed by a posterior annuloplasty. The postrepair TEE showed grade 1 regurgitation.

Of the 9 patients with more than grade 1 insufficiency at the follow-up TTE, $6(5.3 \%)$ had either grade 2 or 3 regurgitation and required reoperations. Four of the 6 patients had a type II leaflet prolapse repaired with a leaflet resection and annuloplasty band. Three of these 4 had grade 1 regurgitation by TEE after repair, and the fourth had systolic anterior motion. All 4 patients had MV replacements with a mechanical valve. At reoperation, 1 had a dehiscence of the repair, but the other 3 repairs were intact but with new leakage. One of the 6 patients who required reoperation had a type II prolapse with a chordal rupture. The valve was repaired initially with a chordal replacement and annuloplasty band insertion. The postrepair TEE for this patient showed no regurgitation. However, a follow-up TTE showed a grade 2 leak at the posterior annulus. Four months after the first operation, the patient presented with a partial band dehiscence that caused hemolysis necessitating valve replacement. The remaining patient initially had grade 3 mitral regurgitation secondary to type 3 posterior leaflet restriction. The robotic repair consisted of a band annuloplasty, and the initial postrepair TEE showed only trace mitral regurgitation. However, the follow-up TTE showed grade 2 regurgitation with a central jet. Because the patient was symptomatic, the valve was replaced with a bioprosthesis.

There were no operative or midterm deaths; however, there were 11 major adverse events. The 6 that necessitated reoperations were discussed previously. Other complica- 
tions included bleeding (re-exploration, $\mathrm{n}=3$ ), a pericardial effusion (drainage, $\mathrm{n}=1)$, and a myocardial infarction $(\mathrm{n}=$ 1). There were no intraoperative conversions to alternative surgical techniques (eg, sternotomy or thoracotomy enlargement), and there were no da Vinci system-related adverse events. All procedures that were started with the da Vinci system were completed with robotic assistance.

Generalized estimating equations were used to analyze the learning curves associated with da Vinci system MV repairs. This model considers the correlation structure involved with repeated measures for a given surgeon/site participating in the trial. In patients requiring resections, CPB times decreased by 4.3 minutes per progressive case (Figure 1, A). In this same group, the mean aortic crossclamp time decreased by 3.7 minutes per case, and total operative times decreased by 4.4 minutes per case (Figure 1, $B$ and $C$ ).

\section{Discussion}

Continually improving MV repair methods have rendered outstanding results, but sternotomy still remains the approach of choice for most surgeons. Carpentier and others have shown enviable repair results that have persisted for 15 to 20 years, thus establishing this approach as the "gold standard." ${ }^{16}$ Recently, minimally invasive techniques have been developed for valve operations. Partial sternotomies, parasternal incisions, and minithoracotomies were first used to reduce surgical trauma and to minimize hospitalization and transfusions. Beginning in 1995, Cosgrove, ${ }^{2}$ Cohn, ${ }^{1}$ Grossi, ${ }^{17}$ and their associates led this effort, and their results paralleled those of sternotomy-based repairs. ${ }^{1,2,17}$ To date, surgeons at the Cleveland Clinic have performed well over 2500 minimally invasive valve operations by combining direct vision with an upper hemisternotomy and modified perfusion techniques. Their minimal-access patients had less than a $1.0 \%$ mortality, reduced transfusions $(<10 \%)$, and earlier hospital discharge compared with those who had sternotomy. ${ }^{18}$ Complex operations were performed by these surgeons, as evidenced by their first 607 minimally invasive aortic valve operations, in which $25 \%$ were repairs and $26 \%$ were homograft replacements. Cohn has performed more than 1000 minimally invasive aortic and MV operations, with similar excellent results. ${ }^{2}$ His reoperative rate for MV repair was $3.0 \%$, compared with $6.9 \%$ for 893 patients in the 2001 STS database. Similarly, the New York University group reported $375 \mathrm{MV}$ repairs with minithoracotomy, endoaortic balloon occlusion, and direct vision. ${ }^{17}$ Again, low operative mortality (1.1\%) and good results were shown for complex repairs. Of these patients, $89 \%$ had only trace or no residual regurgitation by TEE after the repair.

Despite these and other successful minimally invasive valve operations, most surgeons have not embraced endoscopic methods for MV surgery. Onnasch and associates ${ }^{19}$
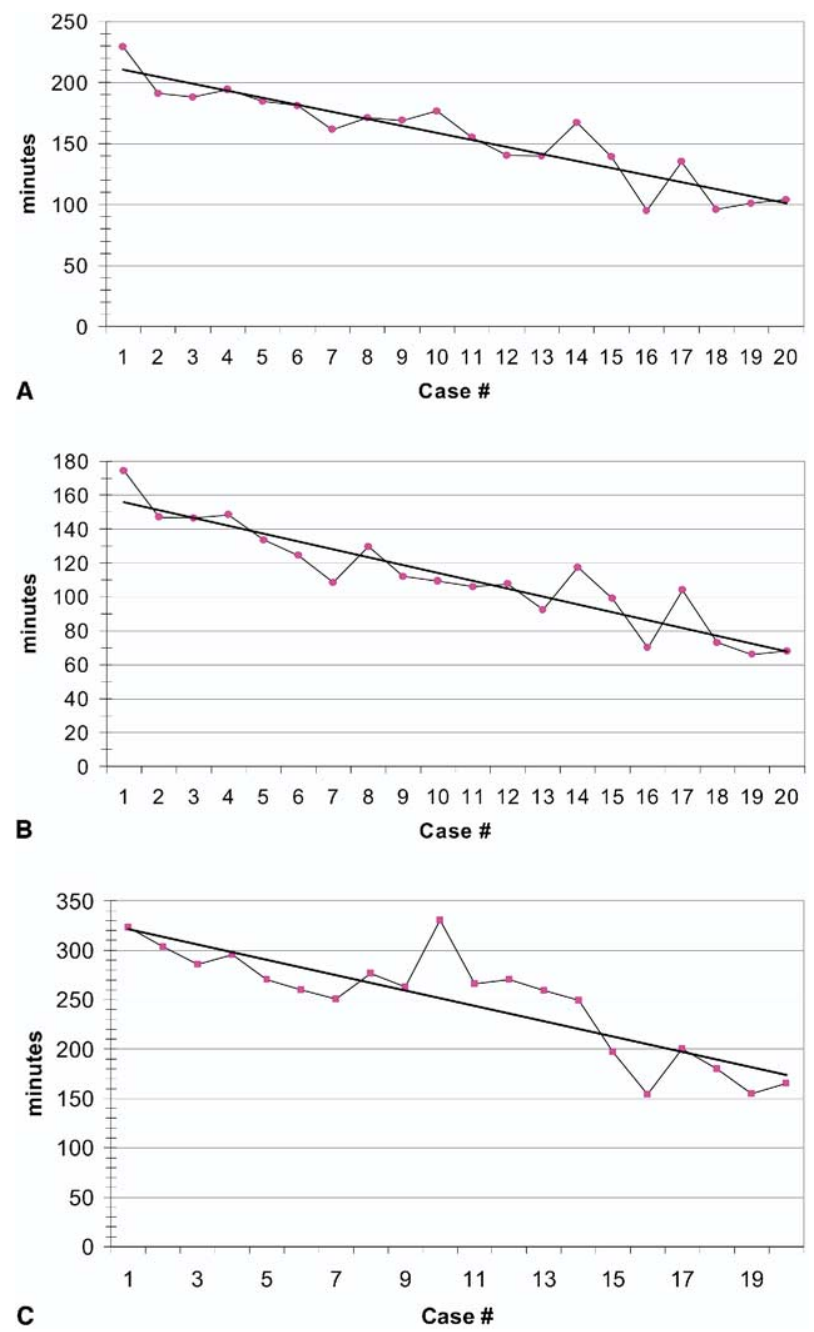

Figure 1. Mean cardiopulmonary bypass (CPB) time (A), crossclamp time (B), and operating time (C) in MV repair cases requiring leaflet resection.

and Chitwood and Nifong ${ }^{18}$ independently showed that endoscopic MV surgery can be performed safely and with "gold standard" results, but in most instances their operations were video assisted rather than totally endoscopic. ${ }^{5}$ In contradistinction, Schroeyers and associates ${ }^{20}$ have shown that excellent MV repairs can be performed endoscopically by using 2-dimensional visualization and endoaortic occlusion. Few surgeons to date have adopted these methods because of the difficult transition from a wide-access, directvision cardiac operation to a completely endoscopic one that requires a combination of new technologies.

By limiting direct access to the valve, visualization becomes impaired, instrument manipulation is encumbered, and surgeon confidence in the safety and quality of the operation may wane. Surgical telemanipulation seems the 
ideal method for operating accurately through the small incisions and in restricted spaces. Robotic technology can provide many potential benefits to cardiac surgeons. Cutaneous incisions can be smaller because of improved optics and instrumentation. Moreover, wristlike articulations transfer the dexterous actions of instrument tips to the plane of the annulus and the papillary muscle level. With the addition of tremor filtration, there is improved precision in tight intracardiac spaces. Moreover, ambidexterity can become a reality for all surgeons. With these devices, leaflet resections, chordal transfers, and sliding plasties can be combined with a band or ring annuloplasty to perform complete repairs. ${ }^{12}$

The results reported herein represent an FDA-approved robotic MV surgery multicenter trial in which experienced MV repair surgeons from 10 centers enlisted patients into a standardized IRB- and FDA-approved protocol. In each patient, the major portion of each operation was performed robotically from a console removed from the operating table. The robotic system performed safely and efficiently, with no operative deaths or conversions due to a system malfunction. Moreover, there were no incision conversions either to a larger thoracotomy or to a median sternotomy.

These patients benefited from minimal musculoskeletal trauma, a low transfusion rate, and early discharge. Although there were no operative mortalities and few complications, 6 patients required reoperations, of which 5 had valve replacements and 1 had a second band annuloplasty. Although these patients had either no or less than grade 1 regurgitation on the postrepair TEE, they presented within 4 months with grade $3 / 4$ regurgitation and symptoms. Repair failures were spread over 4 institutions, all of which had enrolled at least 10 patients in the study. Compared with the STS database, patients in the multicenter robotic trial had significantly lower mortality, fewer neurologic complications, and shorter lengths of hospital stay. Moreover, robotic MV patients tended to have fewer reoperations and overall complications than those in the STS cohort. Transfusion requirements were low (22.3\%) and paralleled those of other minimally invasive valve operative series. ${ }^{21}$ Despite these benefits, crossclamp and perfusion times were significantly longer in the robot trial patients. The most significant complication, other than recurrent leakage, was a myocardial infarction in a patient secondary to right coronary artery air embolism.

In previous studies, residual regurgitation has been reported as an independent risk factor for reoperation. ${ }^{15} \mathrm{Lim}$ and colleagues $^{22}$ showed that approximately $59 \%$ of patients have clinically insignificant regurgitation after a repair. As seen in this series, most repair failures occur, are detected, and are addressed in the early postoperative period. Other authors have shown a mean regurgitant grade of 0.7 after a minimally invasive MV repair. ${ }^{21,23}$ In the 112 patients described herein, the mean grade of mitral regurgitation was 3.7 before surgery and 0.5 after surgery on the TTEs analyzed by the core laboratory.

Operative times were longer in this series compared with conventional sternotomy procedures. However, the learning curves demonstrate a progressive decline in crossclamp, $\mathrm{CPB}$, and resection times, as well as overall operative times, in patients having repairs with or without leaflet resections. One can expect that operations performed early in the series would require longer times than those performed after both the surgeon and team have become familiar with the procedure. This same occurrence has been found in videoassisted MV repair series. ${ }^{24}$ As surgical teams become even more facile in using these devices, perioperative times can be expected to continue to decrease. Moreover, evolving adjunctive technology, such as annuloplasty band clips, may speed these operations even more.

Study limitations were primarily related to the investigation of an optimal study population with few comorbidities in the patients enrolled. FDA inclusion/exclusion criteria resulted in the exclusion of any patients with conditions such as coronary artery disease, mitral stenosis, bileaflet disease, significant aortic or tricuspid valve pathology, mitral annular calcification, morbid obesity, recent myocardial infarction or stroke, and poor ventricular function.

In summary, this multicenter study has shown that MV repairs can be performed safely in low-risk patients with potential patient benefits by multiple surgeons and teams. Despite the prearranged expertise of these surgeons, this series does suggest a higher early reoperative rate with the robotic methods than with other direct-vision, limitedaccess MV repairs. However, these data compare favorably to conventional repairs performed by multiple surgeons through a sternotomy. With the evolution of robotic surgical systems, surgeons and their patients can expect to gain the benefits shown in this study.

\section{References}

1. Cohn LH, Adams DH, Couper, GS, et al. Minimally invasive cardiac valve surgery improves patient satisfaction while reducing costs of valve replacement and repair. Ann Surg. 1997;226:421-6.

2. Cosgrove DM, Sabik JF, Navia JL. Minimally invasive valve surgery. Ann Thorac Surg. 1998;65:1535-8.

3. Navia JL, Cosgrove DM. Minimally invasive mitral valve operations. Ann Thorac Surg. 1996;62:1542-4.

4. Casselman FP, Van Slycke S, Dom H, Lambrechts DL, Vermeulen Y, Vanermen H. Endoscopic mitral valve repair: feasible, reproducible, and durable. J Thorac Cardiovasc Surg. 2003;125:273-82.

5. Felger JE, Chitwood WR Jr, Nifong LW, Holbert D. Evolution of mitral valve surgery: toward a totally endoscopic approach. Ann Thorac Surg. 2001;72:1203-9.

6. Carpentier A, Loulemet D, Le Bret E, et al.Chirugie a coeur ouvert par video-thoracotomie-premeier cas (valvuloplastie mitrale) opere avec success [First open heart operation (mitral valvuloplasty) under videosurgery through a minithoracotomy]. C R Acad Sci III. 1996;319: 219-23.

7. Mohr FW, Falk V, Diegeler A, et al. Minimally invasive port-access mitral valve surgery. J Thorac Cardiovasc Surg. 1998;115:567-74. 
8. Mohr FW, Falk V, Diegeler A, et al. Computer-enhanced "robotic" cardiac surgery: experience in 148 patients. J Thorac Cardiovasc Surg. 2001;121:842-53.

9. Mehmnesh H, Henze R, Lange R. Totally endoscopic mitral valve repair. J Thorac Cardiovasc Surg. 2002;123:96-7.

10. Grossi EA, LaPietra A, Applebaum RM, Ribakove GH, Galloway AC, Baumann FG, et al. Case report of robotic instrument-enhanced mitral valve surgery. J Thorac Cardiovasc Surg. 2000;120:1169-71.

11. Chitwood WR, Nifong LW, Elbeery JR. Complete robotic mitral valve repair: trapezoidal resection with prosthetic annuloplasty. J Thorac Cardiovasc Surg. 2000;120:1171-2.

12. Nifong LW, Chu VF, Bailey BM, Maziarz DM, Sorrell VL, Holbert D, et al. Robotic mitral valve repair: experience with the da Vinci system. Ann Thorac Surg. 2003;75:438-43.

13. Chitwood WR, Nifong LW, Chapman WHH, et al. Robotic surgical training in an academic institution. Ann Surg. 2001;234:475-85.

14. Chitwood WR, Nifong LW. Robotic assistance in cardiac surgery. Probl Gen Surg. 2001;18:9-20.

15. Deloche A, Jebara VA, Relland JY, Chauvaud S, Fabiani JN, Perier P, et al. Valve repair with Carpentier techniques: the second decade. J Thorac Cardiovasc Surg. 1990;99:990-1001.

16. Braunberger E, Deloache A, Berebi A, Abdallah F, Celestin JA, Meimoun $\mathrm{P}$, et al. Very long-term results (more than 20 years) of valve repair with Carpentier's techniques in non-rheumatic mitral valve insufficiency. Circulation. 2001;104:1-8.

17. Grossi EA, Galloway AC, Lapietra A, Ribakov GH, Ursommano P, Delianides J, et al. Minimally invasive mitral valve surgery: a 6-year experience with 714 patients. Ann Thorac Surg. 2002;74:660-4.

18. Chitwood WR, Nifong LW. Limited access mitral valve surgery: videoscopic and robotic techniques. In: Gardner TJ, Spray TL, editors. Operative cardiac surgery. London: Arnold; 2004. p. 289-304.

19. Onnasch JF, Schneider F, Falk V, Mierzwa M, Bucerius J, Mohr FW. Five years of less invasive mitral valve surgery: from experimental to routine approach. Heart Surg Forum. 2002;5:132-5.

20. Schroeyers P, Wellens F, De Geest R, Degrieck I, Van Praet F, Vermuellen Y, et al. Minimally invasive video-assisted mitral valve surgery: our lessons after a 4-year experience. Ann Thorac Surg. 2002;72:S1050-4.

21. Aklog L, Adams DH, Couper GS, et al. Techniques and results of direct-access minimally invasive mitral valve surgery: a paradigm for the future. J Thorac Cardiovasc Surg. 1998;116:705-15.

22. Lim E, Ali ZA, Barlow CW. Determinants and assessment of regurgitation after mitral valve repair. J Thorac Cardiovasc Surg. 2002; 124:911-7.

23. Grossi EA, LaPietra A, Ribakove GH, et al. Minimally invasive versus sternotomy approaches for mitral reconstruction: comparison of intermediate-term results. J Thorac Cardiovasc Surg. 2001;121:708-13.

24. Chitwood WR, Elbeery JR, Chapman WHH, et al. Video-assisted minimally invasive mitral valve surgery: the micro-mitral operation. J Thorac Cardiovasc Surg. 1997;113:413-4.

\section{Discussion}

Dr Friedrich W. Mohr (Leipzig, Germany). I would like to congratulate the authors on a very successful prospective multicenter phase II FDA trial performing total endoscopic MV repair in 112 patients by using the Intuitive telemanipulation system. In 1998, Professor Carpentier and I independently performed the first MV repairs by using this system. Optimal visualization, precise cutting, and suturing seemed to be very advantageous as compared with normal endoscopic instruments.

In our own series, we have completed 26 of 28 successful MV repairs, including very complex repairs. We had to learn that the current technology still is suboptimal, and it was very hard to manage simple techniques such as the implantation of a complete remodeling ring and time-consuming knot tying.

During the past 3 years, we favored video-assisted surgery for routine use. However, we are working together with Intuitive on a concept for better teaching and training in endoscopic MV repair by using 2 consoles to apply computer simulation.

This article demonstrates very nicely that this type of MV surgery has been successfully introduced in the United States and has been further developed, especially by Dr Chitwood's group. I want to congratulate all the centers and authors for this tremendous work.

One has to understand that the results being presented reflect the situation of a completely new operation, and one has to accept that every surgeon has had to learn how to do it. There was no mortality, and there were no major intraoperative complications or neurologic deficits. The initial success rate of MV repair was very high: $99.1 \%$.

I would like to ask 3 questions. You were mentioning that every team went through a special training for robotic MV surgery before clinical application. Can you elaborate on this and describe what was deemed to be necessary? Did all the centers have experience in minimally invasive video-assisted MV surgery?

Ten centers contributed to the study. Patient enrollment varied between 3 and 22 patients depicting different stages in the learning curves. Furthermore, you could demonstrate a clear improvement per given case concerning mean times of surgery, mean crossclamp times, and so on. How many patients should one operate on to feel comfortable?

The failure rate of successful MV repair was 9 (8\%) of 112 within 1 month; 6 patients needed reoperation. Even if this reoperation rate compares favorably to the STS database rates, it seems high to me, because you were dealing with highly selected patients with uncomplicated MV disease. Do you think this may be due to the compromise of using a posterior band instead of a remodeling ring in such patients or inadequate compression by the suture technique?

Dr Nifong. Professor Mohr, thank you very much for your kind words and also legitimate criticisms. It is an honor to have our article reviewed by a pioneer in the field of robotic and minimally invasive cardiac surgery. Your team in Leipzig has contributed a great deal to this field.

To answer your first question regarding training for robotic mitral valve surgery, we have an intense 2-day program for training surgical teams. This occurs after teams have completed the "system" training, which is when they learn how to use the system and perform troubleshooting for potential problems. Valve training includes live case observation in the operating room followed by didactic discussion and review of the case. Issues related to peripheral cardiopulmonary bypass, aortic occlusion, cardioplegia administration, and deairing are reviewed and discussed.

We then spend a day and a half in the robotic laboratory using inanimate models, porcine hearts, and cadavers. We review each step of the procedure, including patient positioning, incisions, exposure, cannulation, retraction, and positioning of both the robotic surgical cart and instruments. All centers involved in the multicenter trial had experience in minimally invasive mitral valve surgery. However, at this time we are training teams with less minimally invasive or videoscopic experience, and they perform very well.

To answer your second question, we have performed 81 robotic mitral valve procedures and recently reviewed all the 
data with learning curves. In our experience, one should expect to complete approximately 15 cases before times begin to decrease.

To answer your third question, we are very sensitive to the issue regarding the 6 patients who required reoperation. One concerning issue is that none of those patients had more than grade 1 mitral regurgitation by postrepair transesophageal echocardiography, and these readings were by an off-site cardiologist blinded to the institution and procedure performed. At follow-up, these patients had advanced to grade 2 or worse mitral regurgitation.
As you are aware, it is quite difficult to manage a more rigid ring in the small space of the left atrium by using the robotic system; however, it can be done, and we have recently performed 2 valve replacements. We are currently working on ideas related to a new type of annuloplasty ring that may answer this problem and allow one to perform a full remodeling annuloplasty, if needed.

We do not believe that the suturing technique is a problem. The high magnification of vision systems allows the surgeon to see the compression and tightness of the knots. Air knots are easily seen and avoided.

Thank you again for reviewing our article.

\section{Online-www.aats.org}

Now you can get The Journal of Thoracic and Cardiovascular Surgery online. The Journal online brings you faster delivery time, easy searching of current and back issues, links to PubMed, AATS, WTSA, and other important sites, and more. Visit the Journal online today.

\section{Receive tables of contents by e-mail}

To receive the tables of contents by e-mail, sign up through our Web site at http://www.mosby.com/jtcvs

Choose E-mail Notification

Simply type your e-mail address in the box and click the Subscribe button.

Alternatively, you may send an e-mail message to majordomo@mosby.com.

Leave the subject line blank and type the following as the body of your message: subscribe jtcvs_toc

You will receive an e-mail to confirm that you have been added to the mailing

list.

Note that TOC e-mails will be sent out when a new issue is posted to the Web site. 